\section{What's in a waiting list?}

\author{
H F SANDERSON
}

Since the creation of the National Health Service in 1948 the time that patients have had to wait for inpatient treatment of nonurgent conditions has concerned the public, the profession, and politicians. There have been regular Parliamentary questions on the total numbers of waiting patients, ${ }^{1}$ comments and criticisms from other countries (W A Glaser, Columbia University, New York, personal communication), and working party reports. ${ }^{2}$ Throughout comments have been frequent about the difficulty of interpreting waiting-list statistics. ${ }^{3}$ The recent claims by the Government on the fall in numbers of waiting patients ${ }^{4}$ and the effects of industrial action on the admission of patients have added urgency to the debate on the importance of waiting lists. ${ }^{5}$

One implicit assumption has been that the size of the waiting list or length of waiting time in some way relates to the adequacy of resources for treatment. Thus large waiting lists or long waiting times are taken as an indication that more resources are required. The weakness of this assumption is that the criteria for placing patients on a waiting list are not constant in time and place. Most patients waiting for hospital admission wait for cold surgical procedures such as hernia repair, varicose vein stripping, cataract extraction, and vaginal repair-chronic conditions that gradually become more severe. These conditions start with minimal symptoms, causing little disability, but worsen (figure)

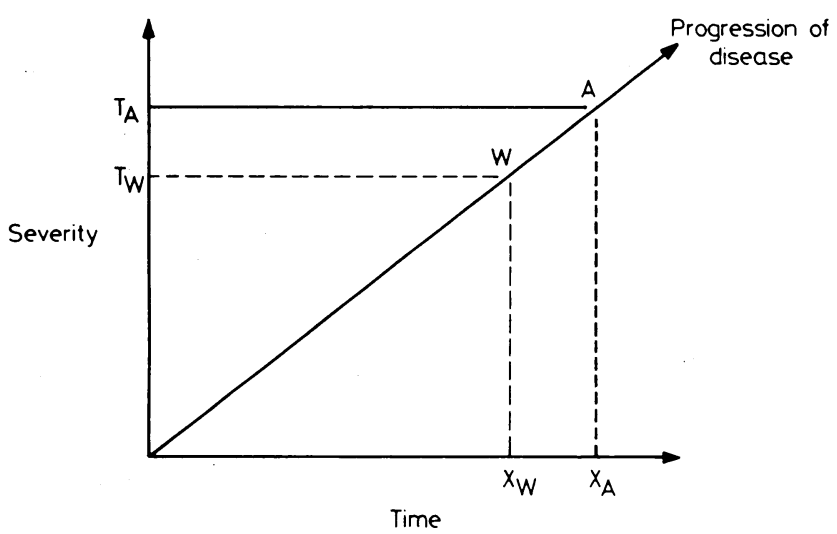

Thresholds for waiting-list placement and admissions for surgery.

until at some point the benefits of treatment are judged to outweigh the risks and discomfort. At this point in the ideal world the patient would be admitted for operation. This course of progress may be represented diagrammatically (figure), so that in the ideal world when the patient becomes suitable for treatment (at time $\mathrm{X}_{\mathrm{A}}$ ) he crosses the admission threshold $\mathrm{T}_{\mathrm{A}}$ and is

Department of Community Health, London School of Hygiene and Tropical Medicine, London WC1

H F SANDERSON, MB, MFCM, senior lecturer admitted and operated on. The NHS is not an ideal world so the progress of patients is not constantly monitored, nor are facilities for treatment instantly available. Because of this consultants assess patients in outpatient departments and place those who they think are likely to cross the operation threshold in the foreseeable future (or who have already crossed it) on the waiting list for admission. Thus a second threshold level $\left(T_{\mathrm{W}}\right)$ (below the admission threshold) is set at which patients are judged suitable for placing on the waiting list.

The implication of the waiting-list threshold, therefore, is that if the patient has not yet passed the admission threshold at the time of the outpatient consultation but has passed the waitinglist threshold he may be expected to deteriorate to the level of the admission threshold by the time he reaches the top of the waiting list and is called for admission. For some consultants and conditions this waiting-list threshold may be low, resulting in long waiting lists; for others the threshold may be high, resulting in short waiting lists.

\section{Cataract surgery}

This phenomenon may be readily seen in cataract surgery. Ophthalmic surgeons tend to handle their waiting lists in one of two ways. ${ }^{6}$ They may place all patients with cataracts on the waiting list at their first outpatient attendance in the expectation that by the time of admission the cataract will have progressed sufficiently to merit extraction. Alternatively, they may review all cataract patients at regular intervals, placing patients on the waiting list only when their vision has deteriorated sufficiently to justify early extraction. The first group, with low waiting-list placement thresholds, tends to have long waiting lists. The second group, with high waiting-list thresholds, tends to have short waiting lists.

Despite the difference in waiting-list lengths, however, the degree of visual disability at operation-that is, the operation threshold-is likely to be similar, as may be seen in the table.

Visual disability of elderly patients admitted for simple cataract extraction

\begin{tabular}{|c|c|c|}
\hline & $\begin{array}{c}\text { Short waiting-list } \\
\text { patients } \\
\text { (less than } 6 \text { months) }\end{array}$ & $\begin{array}{c}\text { Long waiting-list } \\
\text { patients } \\
\text { (1 } \frac{1}{2} \text { to } 4 \text { years) }\end{array}$ \\
\hline $\begin{array}{l}\text { Total No of patients } \\
\text { Median distance visual acuity: } \\
\text { Better eye } \\
\text { Worse eye } \\
\text { Able to go shopping alone } \\
\text { Able to cross the road alone } \\
\text { Able to read the newspaper }\end{array}$ & $\begin{array}{c}26 \\
6 / 36 \\
\text { counting fingers } \\
11 / 22^{*}(50 \%) \\
12 / 24^{*}(50 \%) \\
8 / 26^{*}(31 \%)\end{array}$ & $\begin{array}{c}47 \\
6 / 36 \\
\text { counting fingers } \\
16 / 35^{*}(46 \%) \\
15 / 38^{*}(39 \%) \\
16 / 45^{*}(35 \%)\end{array}$ \\
\hline
\end{tabular}

*Less than the total because the question was not applicable for non-visual reasons for some patients.

This shows the visual disability of patients under the care of ophthalmic surgeons at a provincial teaching hospital, ${ }^{7}$ and there is virtually no difference between patients under consultants with short waiting lists (less than six months) and those with long waiting lists (one and a half to four years). The difference in 
waiting time is due to the differences in waiting-list thresholds used by these consultants.

Thus casual inspection of waiting-list sizes and waiting times could prompt misleading conclusions. The inference that a long waiting list for one consultant reflects a high pressure of work and inadequate resources is clearly wrong and attempts at correcting the imbalance without understanding the underlying reasons for it would be futile.

Though the differences in methods of working are obvious in cataract surgery, similar differences may exist between different hospitals and districts not only in ophthalmology but in other specialties, and, even if the waiting-list thresholds do not vary, the threshold of referral by general practitioners may do (because of differences in outpatient appointment times) or the threshold of self-referral of patients to their own general practitioner may vary, and these will also affect the waiting times. It has been said that long waiting lists are often used by consultants as a weapon or a status symbol ${ }^{7}$ and allegations that waiting lists are manipulated to promote private practice have also been made. ${ }^{8}$ It is easy to see how such manipulations may be made by lowering or raising the waiting-list placement threshold without in any way affecting the admission threshold. The remedies proposed to deal with these problems by day surgery, redeployment of beds and manpower, ${ }^{10}$ cessation of committee work, ${ }^{7}$ or improved operating theatres, will clearly have little permanent effect on the problems and may even lead to some unnecessary surgery.

\section{Effects of threshold}

The discussion of waiting lists has focused for too long on the implicit assumption that the problem lies in the level of the admission threshold and that lowering this will resolve it. Too little attention has been given to the problem of the effects of the waiting-list threshold on the waiting-list size and the way that this can vary between surgeons, hospitals, and different points in time.

The real problem is that we are trying to judge admission thresholds by the proxy variables waiting-list size and waiting time without knowing much about the variables that influence them (waiting-list threshold and morbidity in the community). The proxy variables have then been used to make judgments about the appropriateness of admission thresholds and hence of resource availability both at an absolute level and as a comparison between places and points in time. This would be acceptable if we were reasonably sure that waiting-list placement thresholds did not vary much. But knowledge of different systems of waitinglist management-for instance, as in ophthalmology or the use of booked cases ${ }^{12}$ - the observation of changes in practice after the introduction of new resources, ${ }^{13}$ and the observed differences in clinical management by individual consultants ${ }^{1415}$ make it likely that differences in placement thresholds do exist. Thus the use of waiting-list size as a proxy for admission threshold becomes quite untenable. We need to recognise that the size of the waiting-list is not directly related to the adequacy of resources to meet the needs of the community, the efficiency of the hospital service, or anything else except the difference between the waiting-list and admission thresholds.

To suggest, however, that the answer to these problems lies in measuring admission thresholds is not helpful. There are difficult methodological problems in constructing scales of severity and in validating them against external standards. Much effort has been put into developing broad-spectrum health status indices but little of this work has resulted in useful and reliable scaling methods. Attempts to produce singlecondition severity scales have also been made, ${ }^{16} 17$ but, again, there have been substantial problems in ensuring the validity and reliability of these scales. ${ }^{18}$ Added to the methodological problems are logistic problems of obtaining reliable data on patients as they are admitted to hospital. For thresholds to be compared from place to place and time to time the data need to be collected cheaply and accurately and at present this is not possible. There have been developments of methods of assessing severity from the routinely collected diagnostic and operation data, ${ }^{19}$ and possibly this kind of approach could provide accurate and reliable enough information about severity to be an indicator of the threshold of admission. This stage is, however, some way away and there is at present no useful routine information on the threshold of admission in different places. This does not mean, however, that in the absence of reliable threshold data it is worth while continuing the time-honoured precedents of examining and publishing data on the size and length of waiting lists. The absence of any source of valid information cannot transform meaningless statistics into a useful management tool.

\section{References}

${ }^{1}$ Anonymous. Any way out of the waiting lists ? Lancet 1978 ;i:397-8.

2 Department of Health and Social Security. Orthopaedic services: waiting time for outpatient appointments and inpatient treatment. London: HMSO, 1981.

${ }^{3}$ Department of Health and Social Security. Waiting for hospital treatment. Harrogate seminar report. London: DHSS, 1980.

${ }^{4}$ Anonymous. The mystery of waiting lists and waiting times. Lancet 1981 ;ii: 1122.

${ }^{5}$ Anonymous. How secure are figures for waiting NHS patients ? Lancet 1981 ;ii:1179-80.

6 Philips CI, Vaid RL. An ophthalmic consultant's outpatients clinics. Trans Ophthalmol Soc UK 1977;97:506-7.

${ }^{7}$ Sanderson HF. Thresholds in cataract surgery. London: University of London, 1978. Thesis.

${ }^{8}$ Williams B. The use and misuse of bed occupancy and waiting list figures. Lancet 1968; i 1029-30.

${ }^{10}$ Ministry of Health. Annual report 1964. Cmnd 2688. London: HMSO, 1965.

12 Department of Health and Social Security. Notes on good practicesadministrative arrangements for planned early discharge of patients undergoing surgery. London: DHSS, 1978.

${ }^{13}$ Dodson RM. Planning for outpatient surgery. Lancaster: University of Lancaster, 1971. Thesis.

${ }^{14}$ Roos NP, Roos LL, Henteleff PD. Elective surgical rates-do high rates mean lower standards? Tonsillectomy and adenoidectomy in Manitoba. $N$ Engl f Med 1977;297:360-5.

15 Fernow LC, McColl I, Mackie C. Firm, patient, and process variables associated with length of stay in four diseases. Br Med 7 1978;i:556-9.

${ }^{16}$ Baker SB, O'Neill B, Haddon W Jr, Long WB. The injury severity score: a method for describing patients with multiple injuries and evaluating emergency care. Trauma 1974;14:187-96.

17 Gustafsen DH, Holloway DC. A decision theory approach to measuring severity of illness. Health Serv Res 1976;10:97.

18 Gibson G. Indices of severity for emergency medical evaluative studies: reliability, validity, and data requirements. Int $\mathcal{F}$ Health Serv 1981;11: 597-622.

19 Fetter RB, Shin Y, Freeman JL, Averrill RF, Thompson JD. Case mix definition by diagnosis-related groups. Med Care 1980;18, suppl 2: 1-53.

(Accepted 20 October 1982) 